\title{
The Changes of Mucous Cells in the Skin of Van Fish [Alburnus tarichi (Güldenstädt, 1814)] during Freshwater Adaptation
}

\author{
Fadime İRIBUĞDAY*, Ahmet Regaib OĞUZ \\ Department of Biology, Faculty of Science, Van Yüzüncü Yıl University, Van, TURKEY \\ ORCID ID: Fadime İRIBUĞDAY: https:// orcid.org/0000-0003-4211-6100; Ahmet Regaib OĞUZ: https://orcid.org/0000-0001-6431-0508
}

\begin{abstract}
Received: 11.06.2020 Accepted: 03.09.2020 Published online: 20.09.2020 Issue published: 31.12 .2020
Abstract: Van fish, an anadromous fish, migrate in flocks to fresh water poured into the lake from the extreme conditions of Van Lake for breeding. The fish that complete their breeding return to the lake for feeding. In these two different aquatic environments, skin is exposed to different physicochemical effects of water. In the present study, morphometric and histological changes in mucous cells of the skin during reproductive migration were studied. The thickness of the epidermis was found to be thicker in the freshwater than in the lake environment. It has been determined that both the diameter and the chemical content of the mucus cell vary in different aquatic environments (freshwater and lakes). For this reason, it is thought that mucus cells are present in different types in the skin of Van fish. Also, these changes are different in several parts of the body (dorsal and lateral). These histological and histochemical changes in Van Fish are thought to be necessary for the adaptation of fish to aquatic environments.
\end{abstract}

Keywords: Van Lake, Histology, Epidermis, Mucous cells.

\section{Van Balığı [Alburnus tarichi (Güldenstädt, 1814)] Derisindeki Mukus Hücrelerinin Tatlı Su Adaptasyonu Sırasında Değişimi}

Öz: Anadrom bir balık olan Van balığı, üremek amacıyla Van Gölünün ekstrem şartlarından göle dökülen tatlı sulara doğru sürüler halinde göç eder. Aynı şekilde üremesini tamamlayan balıklar tekrar beslenmek amacı ile göl ortamına geri dönerler. Bu iki farklı sucul ortamda deri, içerisinde bulunduğu ortamın farklı fizikokimyasal etkilerine maruz kalır. Bu çalışmada, Van balığının derisindeki mukus hücrelerinin üreme göçü sırasında histokimyasal ve morfometrik değişimleri incelendi. İncelenen balıkların mukus hücrelerinin farklı sucul ortamlarda (akarsu ve göl) hem çapının hem de kimyasal içeriğinin değişim gösterdiği belirlendi. Bu değişiklikler vücudun farklı bölgelerinde de (dorsal ve lateral) farklılık gösterdi. Van Balığında gözlenen bu histolojik ve histokimyasal değişimlerin balığın sucul ortamlara adaptasyonu için zorunlu olduğu düşünülmektedir.

Anahtar kelimeler: Van Gölü, Histoloji, Epidermis, Mukus hücreleri.

\section{Giriş}

Balıklarda deri boşaltım ve solunum gibi hayati olaylarda rol oynar. Ayrıca farklı pigment maddeleriyle de renklenmeden sorumludur. Bu özelliklerinin dışında bazı balık türlerinde deri zehir bezleri ve elektrik organları gibi özelliklere sahiptir. Diğer omurgalı hayvanlarda olduğu gibi, balıkların da derisi alt deri (dermis) ve üst deri (epidermis) denilen iki tabakadan oluşmuştur (Elliot, 2011). Bu tabakalara ilave olarak bazalde hipodermis tabakası da bulunmaktadır. Çok katlı epidermis hücrelerinin bazalınde bulunan ve apikal kısımda hasar gören epidermis hücrelerinin yerine yenisini üreten stratum germinativum ad1 verilen mitotik aktivitesi yüksek bir tabaka bulunur (Timur, 2008). Epidermis tabakasındaki non-keratinize epitel hücre tabakasının kalınlığının 3 ile 20 hücre arasında değiştiği bildirilmiştir (Ferguson, 1989).

Deri dış ortam ile temas halinde olduğu için sürekli olarak hücre kaybına uğrar. Bu nedenle epidermisdeki diğer epiteliyal hücreler gibi mukus hücreleri de mitojenik aktiviteye sahip olup bölünerek sayılarını artırır. Epidermis tabakasında epitel hücreler haricinde mukus hücreleri de önemli yere sahiptir. Geniş ovoid şekilli mukus hücrelerinin oluşturduğu bezler kısa bir kanal ile pulların arasından vücut yüzeyine mukus salgısı salarlar. Mukus hücrenin bazal kısminda yer alan nükleusları yassı şekillidir (Baran \& Timur, 1983). Mukus hücreleri epidermisteki bazal hücrelerden farklılaşırlar (Takashima \& Hibiya, 1995).

Mukus, sülfat ve karboksil radikallerini içeren polisakkaritler bileşimidir (Takashima \& Hibiya, 1995). Mukus vücut etrafında film gibi bir tabaka oluşturarak su basıncının yüzmeye etkisini azaltır ve vücudun iç kısmını mikroorganizmalardan ve invazyonundan korur (Alexander \& Ingram, 1992; Shephard, 1994; Takashima \& Hibiya, 1995). Mukus sayesinde vücudun dış kısmı devamlı olarak kaygan kalır ve bu kayganlık balığın içinde bulunduğu ortamda kolayca hareket etmesini ve yaralanmalardan kolayca korunmasını sağlar (Alpbaz, 1990). Ayrıca mukus, diş derideki mikrobiyal çoğalmayı ve parazitik enfeksiyonları engeller. İmmün sistemin önemli bileşenleri olan immunglobulinler, lizozim, komplement ve lektinler mukus salg1sı içerisinde de yoğun olarak bulunur (Nielsen \& Esteve-Gassent, 2006). Ayrıca mukus salgısı peroksidaz, proteaz, fosfataz gibi enzimleri içerir (Brown, Arnesen, Rinne, \& Hjelmeland, 1990; Iger \& Abraham, 1990; Iger \& Wendelaar Bonga, 1994). Hücrelerden salgilanan mukus miktarı stres, enfeksiyon, kirleticiler, fiziksel ve kimyasal hasarlar gibi 
etkilerle artar. Aynı zamanda mukus salgısı osmoregülasyon, solunum, hastalıklara karşı direnç için önemli bir faktör olup (Shephard, 1994), parazit ve patojenlere karşı çok iyi bir doğal savunma mekanizmasidir (Fletcher, 1978). Mukus salgilayan hücreler tarafından sürekli yenilenen mukus tabakası, balık yüzeyi üzerinde tehlikeli olabilecek mikroorganizmaların çoğalmasını engeller (Clem et al., 1996; Mughal, Farley-Ewens, \& Manning, 1986). Mukus içerisinde bulunan komplement mikroorganizmalara karş1 savunmada önemli bir antimikrobiyal maddedir (Zaccone, 1983; Boshra, Li, \& Sunyer, 2006; Magnadottir, 2006; Demir 2009).

Van Gölü, Türkiye'nin en büyük gölüdür. Ayrıca dünyada sodalı göller arasında en büyük göllerden birisidir. Göl yüksek pH (9.8), yüksek alkalinite (153 $\mathrm{mEqxl}^{-1}$ ) ve acı su (tuzluluk \%o22) özelliğindedir. Bu özelliklerinden dolayı tek bir omurgalı türü ve az sayıda omurgasız türlerini barındırmaktadır (Danulat \& Selçuk, 1992; Oğuz, 2015a,b). Balık üreme zamanında göl ortamından tatlı sulara sürüler halinde geçiş yapar. Bu göç sırasında tatlısuların göle aktığı kısımlarda belirli bir süre bekleyerek gerekli adaptatif değişimleri gerçekleştirir. Üremesini tamamlayan balıklar herhangi bir bekleme yapmadan direkt olarak göle geri dönerler.

$\mathrm{Bu}$ çalışmada fizikokimyasal olarak farklılık gösterdiği daha önceki çalışmalarla ortaya koyulan Van Gölü ve göle dökülen tatlı su kısımlarından yakalanan Van Balığı (Alburnus tarichi)'nın dorsal ve lateral kısımlarından alınan deri mukus hücrelerinin morfometrik ve histokimyasal değişimlerinin belirlenmesi amaçlandı.

\section{Materyal ve Metot}

\subsection{Balık}

İncelemeye alınan balıklar, göl ortamından (Van Yüzüncü Yıl Üniversitesi açıklarından) fanyalı ağlar ve üreme göçü sırasında (Nisan - Temmuz) ise Karasu Çayından serpme ağlarla yakalandı. Her iki alandan da $10^{\prime}$ ar adet balık yakalandı. Bu çalışmada üreme olgunluğuna sahip III yaş Van Balıkları kullanıldı. Balıklar fenoksi etanol (320 $\mu \mathrm{l} / \mathrm{L})$ ile anestezi edildikten sonra dorsal (baş bölgesinin arka kısmından) ve lateral bölgelerden keskin bistüri yardımıyla deri örnekleri alındı ve Bouin fiksatifi içerisine konuldu.

Balıklar üzerinde çalışma yapılabilmesi için gerekli olan izinler Gıda, Tarım ve Hayvancılık Bakanlığından (75548883/600-738) ve Van Yüzüncü Yil Üniversitesi, Hayvan Deneyleri Yerel Etik Kurulu başkanlığından (26.01.2017 tarih 2017/01 sayılı onay) alınmıştır.

\subsection{Histolojik ve morfometrik analizler}

Deri örnekleri, Bouin fiksatifi içerisine alındı ve 24 saat $+4^{\circ} \mathrm{C}^{\prime}$ de buzdolabinda bekletildi. Dokular daha sonra \%70'lik etil alkol içerisine alındı. Dokular, yükselen alkol (\%70-\%100) ve ksilol serilerinden geçirildikten sonra parafin bloklar içerisine gömüldü. Daha sonra bu bloklardan rotary mikrotom (Microm HM 320, Germany) yardımıyla $5 \mu \mathrm{m}$ kalınlığında kesitler alınarak Periyodik Asit Schiff (PAS), Alcian Blue (AB) pH 2,5, Aldehit fuksin (AF) ve $\mathrm{AF} / \mathrm{AB} \mathrm{pH} 2.5$ boyaları ile boyand. Mukus hücre içeriklerindeki nötral glikoproteinleri işaretlemek için Periyodik Asit Schiff, asidik glikoproteinler için Alcian
Blue ve sülfatlı asidik glikoproteinleri işaretlemek için ise Aldehit fuksin boyaları kullanıldı. Kesitler 1 şık mikroskobunda incelenerek fotoğrafları çekildi (LAS, Leica, Almanya). Mukus hücreleri sayıldı ve hücrelere ait alanlar her iki bölgeden alınan örneklerde Leica Application Suite programı yardımı ile hesapland1.

\section{3. İstatistiksel analiz}

Elde edilen veriler ortalama \pm ortalamanın standart hatası olarak verilmiştir. Gruplar arasındaki fark tek yönlü varyans analizi ile farkın derecesi ise Duncan testi ile belirlenmiştir. $\mathrm{P}<0.05$ istatistiksel olarak anlamlı kabul edildi.

\section{Bulgular}

Van Balığı derisinin epidermis bölgesinin apikal ve orta kısmında çok sayıda tek hücreli mukus hücresi gözlendi (Şekil 1D). Van Balığı'nda mukus salgılayan hücreler göl ve akarsudan yakalanan balıkların dorsal (kafa) ve lateral bölgelerinden alınan kesitlerde PAS, $\mathrm{AB}$ pH 2.5, ve AF boyaları ile pozitif olarak boyand. Derideki mukus hücrelerinin ürettiği mukus miktarı göl ve akarsu lokalizasyonuna bağlı olarak değişiklik göstermiştir (Şekil $1-4)$.
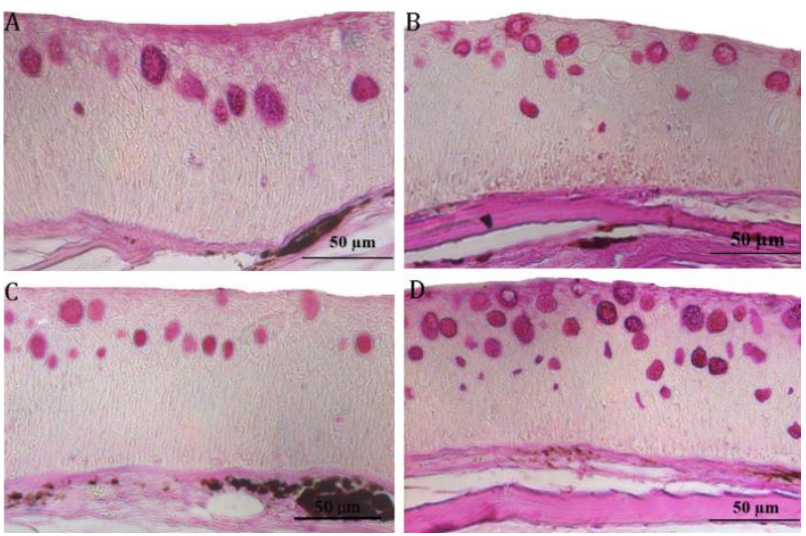

Şekil 1. Van Balığı derisinin Periyodik Asit Schiff ile boyanması A) Göl dorsal B) Akarsu dorsal C) Göl lateral D) Akarsu lateral.

Figure 1. Periodic Acid-Schiff stained cross-sections of the skin of Van fish A) Lake-dorsal B) Freshwater-dorsal C) Lake-lateral D) Freshwater-lateral.

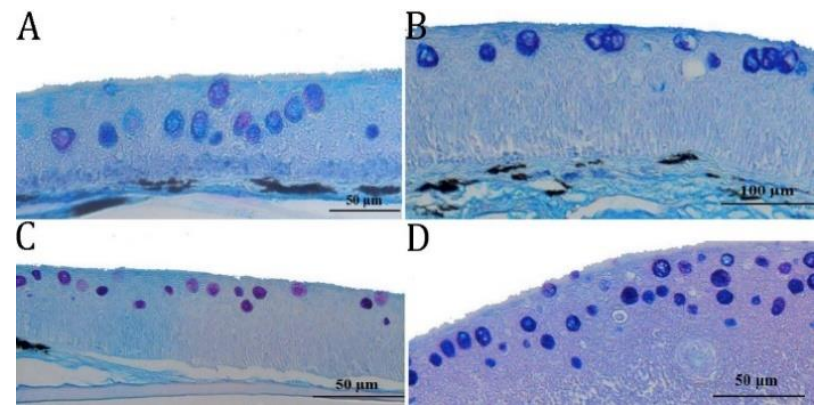

Sekil 2. Van Balığı derisinin Aldehit Fuksin/Alcian Blue pH 2.5 Boyaması A) Göl dorsal B) Akarsu dorsal C) Göl lateral D) Akarsu lateral.

Figure 2. Aldehyde FuchsinAlcian Blue $\mathrm{pH} 2.5$ stained crosssections of the skin of Van fish A) Lake-dorsal B) Freshwaterdorsal C) Lake-lateral D) Freshwater-lateral.

Dorsal kisımdan alınan kesitlerdeki mukus hücrelerinin alanları büyük iken lateral kısımda bulunan mukus hücrelerinin alanları daha küçük olduğu belirlenmiştir (Şekil 5) $(p<0.05)$. Ancak dorsal veya lateral 
bölgelerdeki mukus hücre alanları balık örneklemesinin yapıldığı göl ve akarsu ortamları arasında karşılaştırıldığında herhangi bir farkın olmadığı gözlendi.

Mukus hücre çapları gerek sucul alanlar gerekse kesit alınan bölgelerde farklılık göstermiştir $(p<0.05)$. Göl ortamından alınan örneklerdeki mukus hücre çapları akarsu örneklerine göre daha büyüktür (Şekil 6).

Yapılan epidermis kalınlığı ölçümlerinde gölden alınan örneklerin epidermis kalınlığı akarsu örneklerine göre daha fazladır $(\mathrm{p}<0.05)$. Aynı ortamdan örneklenen balıkların lateral bölge epidermis kalınlıkları dorsal epidermis kalınlıklarına göre daha kalın olduğu belirlense de istatistiksel olarak önemsizdi (Şekil 7).

A

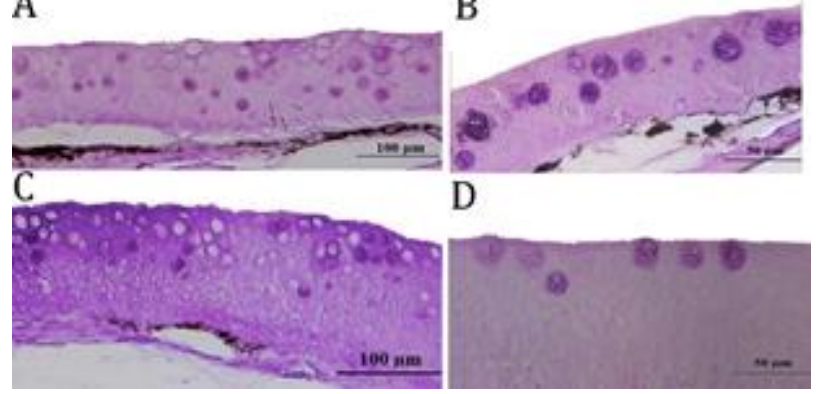

Şekil 3. Van Balı̆̆ı derisinin Aldehit Fuksin (AF) ile boyaması A) Göl dorsal B) Akarsu dorsal C) Göl lateral D) Akarsu lateral.

Figure 3. Aldehyde Fuchsin (AF) stained cross-sections of the skin of Van fish A) Lake-dorsal B) Freshwater-dorsal C) Lake-lateral D) Freshwater-lateral.
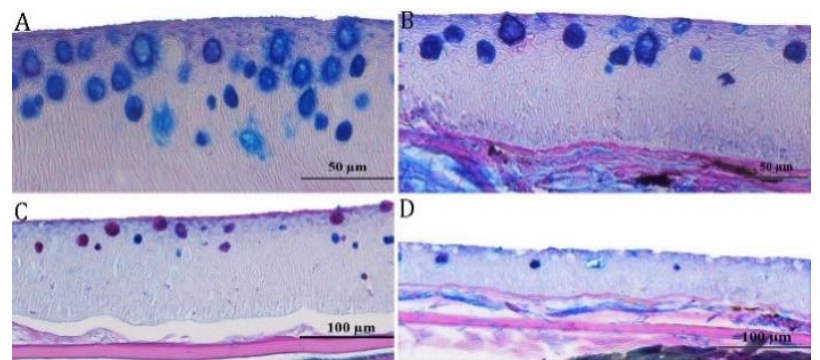

Şekil 4. Van Balığı derisinin PAS/AB pH 2.5 ile boyanması. A) Göl dorsal B) Akarsu dorsal C) Göl lateral D) Akarsu lateral.

Figure 4. PAS/AB pH 2.5 stained cross-sections of the skin of Van fish A) Lake-dorsal B) Freshwater-dorsal C) Lake-lateral D) Freshwater-lateral.

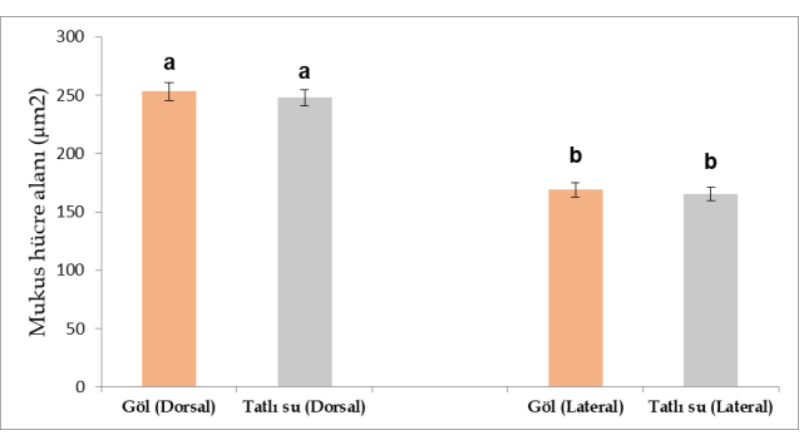

Şekil 5. Van Balığı derisindeki mukus hücre alanlarının karşılaştırılması (n: 40) [farklı harfler gruplar arasındaki istatistiksel farklılığ1 göstermektedir $(\mathrm{p}<0.05)]$.

Figure 5. Comparison of mucus cell areas of the skin of Van fish (n: 40) [different letters show the statistical difference between the groups $(\mathrm{p}<0.05)]$.

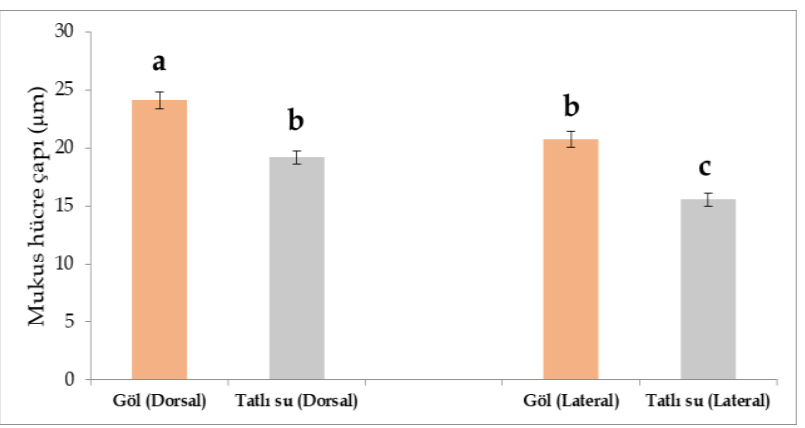

Şekil 6. Van Balığı derisindeki mukus hücre çaplarının karşılaştırılması (n: 30) [farklı harfler gruplar arasındaki istatistiksel farklılığı göstermektedir $(p<0.05)]$.

Figure 6. Comparison of mucus cell diameters of the skin of Van fish (n: 30) (different letters show the statistical difference between the groups $(\mathrm{p}<0.05)]$.

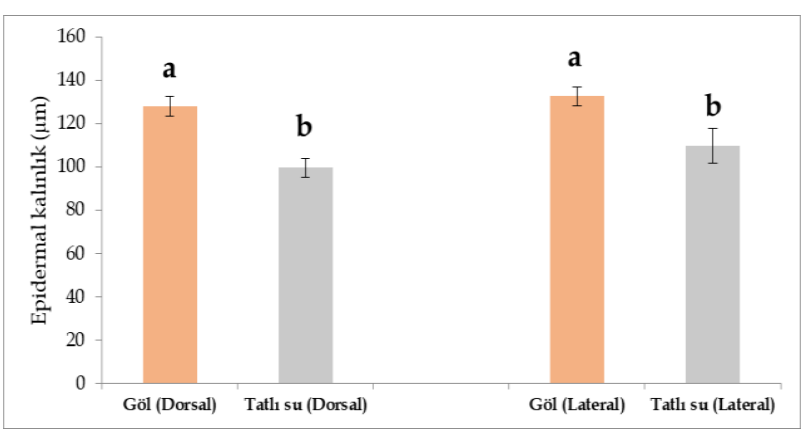

Sekil 7. Van Balığı derisinde epidermal kalınlığın karşılaştırılması (n: 30) [farklı harfler gruplar arasındaki istatistiksel farklılı̆̆ göstermektedir $(\mathrm{p}<0.05)]$.

Figure 7. Comparison of the epidermal thickness of the skin of Van fish (n: 30) (different letters show the statistical difference between the groups $(\mathrm{p}<0.05)]$.

\section{Tartışma}

Van Balığı her ne kadar Van Gölü gibi ekstrem ortamda yaşasa da derisinin histolojik özellikleri, içerisinde yer

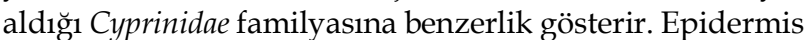
kalınlığı balık türüne, balığın gelişim evrelerine ve farklı vücut bölgelerine göre farklılık göstermektedir. Bu çalışmada gölden alınan örneklerde epidermis kalınlığının akarsudan alınan örneklere göre daha kalın olduğu belirlendi. Fakat epidermis kalınlığı dorsal ve lateral bölgeler arasında istatistiksel olarak önemsizdi. Göl ortamında epidermis kalınlığının fazla olması Van Gölü'nün ekstrem şartlarından kaynaklanmış olabilir. Balıklar tuzlu sularda derilerinden pasif olarak su kaybederler (McCormick, 2001). Van Balığı'nın da tuzluluğuna (\%o22) adapte olmak için diğer mekanizmalara ek olarak epidermis kalınlığını arttırdığı söylenebilir.

Van Balığı epidermisinin en üst tabakası diğer balıklarda olduğu gibi canlı olup mukus ile kaplı yapıdadır (Takashima \& Hibiya, 1995). Bu çalışmada Periyodik Asit Schiff, Alcian Blue ve Aldehit fuksin boyamaları sonucunda Van Balığında gözlenen mukus değişimlerinin sebebi gerek göl ortaminda suyun fizikokimyasal özelliklerine karşı koymak gerekse tatlı suya geçişlerde karşılaşabileceği muhtemel mikrobiyal ve parazitik etkilerden korunmak olabilir. Balıklarda parazitik, mikrobiyal (Dezfuli, Squerzanti, Fabbri, Castaldelli, \& Giari, 2010) ve ağır metallere (Dang et al., 
2019) karşı korunma için mukus hücrelerinin yoğunluğunun ve salgısının artması bu düşünceyi desteklemektedir. Ayrıca mukus salgısının bir diğer görevi de balıklarda iyon düzenlenmesi ve osmoregülasyonda görev almasıdır (Zaccone, 1983; Sephard, 1994). Van Balıklarındaki mukus hücrelerindeki değişimin bir diğer nedeni de balıklardaki kısa süreli göltatlısu adaptasyonlarda rol alması olabilir.

Balıklarda deri, solungaç ve sindirim kanalı gibi organlarda farklı tiplerde mukus hücreleri mevcuttur (Pinky \& Mittal, 2008). Balıkların nötral, asidik veya sülfat içeren farklı glikoprotein özelliklerine sahip mukus hücre içerikleri yaşadıkları ekofizyolojik çevre ile ilişkilidir. Nötral glikoproteinler düşük viskoziteye sahip olup solungaç epitelini fiziksel yaralanmalara karşı koruyabilir, asidik ve sülfatlı glikoproteinler ise balığa yüksek viskozite sağlar ve epitel yüzeyinde potansiyel patojen mikroorganizmaların çoğalmasını önler (Moron, Andrade, \& Fernandes, 2009). Ayrıca Mukus hücre yoğunluğu balık türüne, vücutta bulunduğu bölgeye ve büyüme zamanlarına bağlı olarak da değişiklik gösterir (Yamamoto, Kawai, \& Oshima, 2011). Van Balığında mukus hücrelerinin dorsal ve lateral bölgelerdeki değişimleri, farklı boyalara vermiş oldukları reaksiyonlar, göl ve akarsu gibi iki farklı habitattaki değişimler Van Balığında da farklı tipte mukus hücrelerinin meydana gelmesine neden olduğunu göstermiştir. Özellikle mukus hücresi içerisindeki nötral, asidik, sülfatlı glukokonjugatlar gibi farklı kimyasal içerikleri ve hücre boyutları akarsu ve göl ortamına, ayrıca aynı sucul ortam içerisinde vücutta bulunduğu yere göre değişim göstermiştir.

Van balığında farklı tipteki mukus hücre varlığı morfometrik ölçümlerle de gösterilmiştir. Mukus hücre alan ve çaplarındaki fark göl ve akarsu ortamlarda vücut bölgelerinde istatistiksel olarak önemli bulunmuştur. Benzer bulgular Deltistes luxatus ve Salmo salar L. balıklarında da gözlenmiştir (Lease, Hansen, Bergman, \& Meyer, 2003; Roberts \& Powell, 2003). Dang et al. (2019) mukus hücrelerindeki değişimin gelecekteki çevresel saha çalışmalarında kirletici ve parazit maruziyetinin etkilerinin değerlendirilmesinde başarılı bir şekilde kullanılabileceğini belirtmişlerdir.

Sonuç olarak, Van Balığında derinin ve mukus hücre tiplerinin üreme göçü sırasında iki farklı fizikokimyasal özelliğe sahip sucul ortamda histolojik olarak değişim gösterdiği gözlenmiştir. Sucul ortamlardan bağımsız olarak balığın farklı vücut kısımlarından alınan deride de histolojik değişimler belirlenmiştir. Bu değişimlerin, dünyanın en büyük sodalı göllerinden biri olan Van Gölünde yaşayan balığın adaptasyonu için gerekli olduğu düşünülmektedir.

\section{Kaynaklar}

Alexander, J.B., \& Ingram, G.A. (1992). Noncellular nonspecific mechanisms in fish. Annual Review of Fish Diseases, 2, 249-279. https://doi.org/10.1016/0959-8030(92)90066-7

Alpbaz, A.G. (1990). Deniz Balıkları Yetiştiriciliği. İzmir, Türkiye, Ege Üniversitesi Su Ürünleri Fakültesi Yayın No. 20, 334 pp.

Baran, İ., \& Timur, M. (1983). Balık Bilimi. Ankara, Türkiye, Ankara Üniversitesi Veteriner Fakültesi Yayınları (392), 176 pp.

Boshra, H., Li, J., \& Sunyer, J. O. (2006). Recent advances on the complement system of teleost fish. Fish and Shellfish Immunology, 20, 239-262. https://doi.org/10.1016/j.fsi.2005.04.004
Brown, R., Arnesen, J.A., Rinne, A., \& Hjelmeland, K. (1990). Immuno histological localization of trypsin in mucus-secreting cell layer of Atlantic salmon, Salmo salar L. Journal of Fish Diseases 13, 233-238. https://doi.org/10.1111/j.1365-2761.1990.tb00778.x

Clem, L.W., Bly, J.E., Wilson, M., Chinchar, W.G., Barker, K., Stuge, T., Luft, C., Rheyzyn, M., Hogan, R.J., Van, L.T., \& Miller, N.W. (1996). Fish immunology: The utility of immortalized lymphoid cells- a mini review. Veterinary Immunology and Immunopathology, 54, 137-144. https://doi.org/10.1016/S0165-2427(96)05682-6

Danulat, E., \& Selçuk, B. (1992). Life history and environmental conditions of the anadromous Chalcalburnus tarichi (Cyprinidae) in the highly alkaline Lake Van, Eastern Anatolia, Turkey. Archiv für Hydrobiologie, 126, 105-125.

Demir, N. (2009). İhtiyoloji. Ankara, Türkiye, Nobel Yayın Dağıtım, 4. Bask1, 424 pp.

Dang, M., Pittman, K., Bach, L., Sonne, C., Hansson, S.V., Søndergaard, J., Stride, M., \& Nowak, B. (2019). Mucous cell responses to contaminants and parasites in shorthorn sculpins (Myoxocephalus scorpius) from a former lead-zinc mine in West Greenland. Science of the Total Environment, 678, 207-216. https://doi.org/10.1016/j.scitotenv. $\underline{2019.04 .412}$

Dezfuli, B.S., Squerzanti, S., Fabbri, S., Castaldelli, G., \& Giari, L. (2010). Cellular response in semi-intensively cultured sea breamgills to Ergasilus sieboldi (Copepoda) with emphasis on the distribution, histochemistry and fine structure of mucous cells. Veterinary Parasitology, 174(3), 359-365. https://doi.org/10.1016/i.vetpar.2010. $\underline{08.024}$

Elliot, D.G. (2011). The many functions of fish integument. In: Farrell AP (Ed). Encyclopedia of fish physiology: from genome to environment. San Diego, Academic Press, pp. 471-504. https://doi.org/10.1016/ B978-0-12-374553-8.00285-9

Ferguson, H.W. (1989). Systemic pathology of fish. A text and atlas of comparative tissue responses in diseases of teleosts. Ames: Iowa state university press, $263 \mathrm{pp}$.

Fletcher, T.C. (1978). Defense mechanisms in fish. Biochemical and biophysical perspectives in marine biology. D. C. Malins \& J. R. Sargent (Eds) (Vol IV.). Academic Press, London, 189-222 pp.

Iger, Y., \& Abraham, M. (1990). The process of skin healing in experimentally wounded carp. Journal of Fish Biology, 36, 421-437. https://doi.org/10.1111/j.1095-8649.1990.tb05622.x

Iger, Y., \& Wendelaar Bonga, S.E. (1994). Cellular responses of the skin of carp (Cyprinus carpio) exposed to copper. Aquatic Toxicology, 29, 49-64. https://doi.org/10.1007/BF00318817

Lease, H.M., Hansen, J.A., Bergman, H.L., \& Meyer, J.S. (2003). Structural changes in gills of Lost River suckers exposed to elevated $\mathrm{pH}$ and ammonia concentrations. Comparative Biochemistry and Physiology, 134, 491-500. https://doi.org/10.1016/S1532-0456(03)00044-9

McCormick, S.D. (2001). Endocrine control of osmoregulation in teleost fish. American Zoologist, 41(4), 781-794. https://doi.org/10.1093/icb/ $\underline{41.4 .781}$

Magnadottir, B. (2006). Innate immunity of fish (overview). Fish and Shellfish Immunology, 20, 137-151. https://doi.org/10.1016/j.fsi.2004.09.006

Moron, S.E., Andrade, C.A.D., \& Fernandes, M.N. (2009). Response of mucous cells of the gills of traíra (Hoplias malabaricus) and jeju (Hoplerythrinus unitaeniatus) (Teleostei: Erythrinidae) to hypo-and hyper-osmotic ion stress. Neotropical Ichthyology, 7(3), 491-498. https://doi.org/10.1590/S1679-62252009000300017

Mughal, M.S., Farley-Ewens, E.K., \& Manning M.J. (1986). Effects of direct immersion in antigen on immunological memory in young carp, Cyprinus carpio. Veterinary Immunology and Immunopathology, 12, 181192. https:// doi.org/10.1016/0165-2427(86)90122-4

Nielsen, M.E., \& Esteve-Gassent, M.D. (2006). The eel immune system: present knowledge and the need for research. Journal of Fish Diseases, 29, 65-78. https://doi.org/10.1111/j.1365-2761.2006.00695.x

Oğuz, A.R. (2015a). A histological study of the kidney structure of Van fish (Alburnus tarichi) acclimated to highly alkaline water and fresh water. Marine and Fresh water Behaviour and Physiology, 48(2), 135-144. https://doi.org/10.1080/10236244.2015.1004838

Oğuz, A.R. (2015b). Histological changes in the gill epithelium of endemic Lake Van Fish (Chalcalburnus tarichi) during migration from alkaline water to fresh water. North-Western Journal of Zoology, 11(1), 51-57.

Pinky, Mittal S., \& Mittal, A.K. (2008). Glycoproteins in the epithelium of lips and associated structures of a hill stream fish Garra lamta (Cyprinidae, Cyprinoformes): a histochemical investigation. Anatomia, Histologia, Embryologia, 37, 101-113. https://doi.org/10.1111/j.1439$\underline{0264.2007 .00816 . x}$ 
Roberts, S.D., \& Powell, M.D. (2003). Comparative ionic flux and gill mucous cell histochemistry: effects of salinity and disease status in Atlantic salmon (Salmo salar L.). Comparative Biochemistry and Physiology, 134, 525-537. https://doi.org/10.1016/S1095-6433(02)00327-6

Shephard, H.L. (1994). Function for fish mucus. Reviews in Fish Biology and Fisheries, 4, 401-419. https:// doi.org/10.1007/BF00042888

Takashima, F., \& Hibiya, T. (1995). An atlas of fish histology: Normal and pathological features. Kodansha, Tokyo.

Timur, G. (2008). Balık anatomisi. Ankara, Türkiye, Nobel Yayın Dağıtım, Yayın No: 1332, 184 pp.

Yamamoto, T., Kawai, K., \& Oshima, S. (2011) Distribution of mucous cells on the body surface of Japanese flounder Paralichthys olivaceus. Journal of Fish Biology, 78, 848-859. https://doi.org/10.1111/j.10958649.2010.02898.x

Zaccone, G. (1983). Histochemical studies of acid proteoglycans and glycoproteins and activities of hydrolytic and oxidoreductive enzymes in the skin epidermis of the fish Blennius sanguinolentus pallas (Teleostei: Blenniidae). Histochemistry and Cell Biology, 78(2), 163-175. https://doi.org/10.1007/BF00489495 